\title{
A Tutoria em um Curso de Pedagogia a Distância mediado pela Internet
}

\author{
Mariagela Lenz Ziede, PPGEDU/UFRGS, mariangelaziede@ gmail.com \\ Rosane Aragón, PPGEDU/UFRGS, rosane.aragon@ufrgs.com \\ Crediné Silva de Menezes, FACED/UFRGS, credine@gmail.com \\ Simone Bicca Charczuk, UNISINOS, sibicca@gmail.com
}

\begin{abstract}
Resumo: O trabalho de tutoria em cursos a distância não encontra uma consensualidade na literatura especializada. Essa polissemia reflete diferentes concepções de tutoria, conforme o modelo de EAD adotado. Cada modelo, seguindo sua concepção de aprendizagem e do papel da docência neste processo, estabelece um elenco de atividades e formas de trabalho diferenciadas a serem desempenhadas pelos membros da equipe e, mais especificamente, pelos tutores. Neste artigo apresentamos a concepção e a organização do trabalho de tutoria no contexto do Projeto PEAD, um curso para formação de professores em serviço, oferecido, em sua primeira versão, de 2006/2 a 2011/1.
\end{abstract}

Palavras-chave: tutoria, modelo pedagógico para EAD, mediação pedagógica

\section{The Tutoring in a Distance Education Course mediated by the Internet}

\begin{abstract}
The work of tutoring in distance courses not find a consensuality in literature. This polysemy reflects different conceptions of tutoring as the model adopted EAD. Each model, following its conception of the role of learning and teaching in this process, establishes a list of activities and different forms of work to be performed by team members and, more specifically, by the tutors. This paper presents the design and organization of work of tutoring in the context of Project PEAD, a course for in-service teacher training, offered in its first version in 2006/2 to 2011/1.
\end{abstract}

Keywords: tutoring, pedagogical model for EAD, pedagogical mediation

\section{Introdução}

O trabalho de tutoria em cursos a distância não encontra uma consensualidade na literatura especializada. Essa polissemia reflete diferentes concepções de tutoria, conforme o modelo de EAD adotado. Cada modelo, seguindo sua concepção de aprendizagem e do papel da docência neste processo, estabelece um elenco de atividades e formas de trabalho diferenciadas a serem desempenhadas pelos membros da equipe e, mais especificamente, pelos tutores (PRETI, 2003) (Commonwealth of Learning, 2003).

Neste artigo apresentamos a concepção e a organização do trabalho de tutoria no contexto do Projeto PEAD, um curso para formação de professores em serviço, oferecido, em sua primeira versão, de 2006/2 a 2011/1. Nas seções a seguir apresentamos o contexto do curso, a concepção e o desenvolvimento de tutoria, o processo de formação, a avaliação do trabalho de tutoria no contexto do Projeto PEAD e, por fim, fazemos algumas reflexões sobre o processo de construção da função pela equipe.

\section{O Projeto do Curso}

O Projeto PEAD é um curso de Licenciatura em Pedagogia, na modalidade a distância, para formação em serviço de professores da rede pública de ensino. Em sua primeira 
edição o público atendido foi formado por professores de escolas localizadas em cinco municípios-polos e suas circunvizinhanças.

Considerando a especificidade que deve caracterizar um processo que é, ao mesmo tempo, de formação inicial e continuada de professores, bem como de estudos e pesquisas realizados na UFRGS sobre formação de professores em contextos digitais, o currículo do PEAD foi concebido de maneira interdisciplinar, organizado em eixos temáticos, e com uma contínua interlocução entre as diversas etapas da formação. As disciplinas clássicas foram substituídas por campos de conhecimento, agregando as disciplinas com maior potencial de integração, dando origem às interdisciplinas. Complementando, foi concebida uma interdisciplina denominada Seminário Integrador, com o objetivo de facilitar o diálogo entre as interdisciplinas e ao mesmo tempo favorecer o desenvolvimento de atividades articuladoras. Para favorecer esta intenção, a equipe docente do Seminário Integrador, em cada polo, foi constituída pelos mesmos membros, ao longo do curso.

Seguindo as orientações legais, cerca de $20 \%$ da carga horária semestral foi realizada em atividades presenciais, com encontros dos professores e tutores com os alunos, nos polos. As demais horas, cerca de $80 \%$ do total de 3.225 horas, correspondendo a 215 créditos, integralizados no período de nove semestres, foram desenvolvidas em atividades individuais e cooperativas, realizadas em ambientes digitais, de formas síncrona e assíncrona. Os recursos pedagógicos interativos, para apoio às interdisciplinas, foram produzidos em formato digital e disponibilizados na web.

Em geral, as propostas de atividades partiam de realização de práticas em salas de aula, a partir das quais aconteciam os debates, as trocas de experiências, o confronto de ideias e a análise à luz das contribuições teóricas. Este movimento convergia então para uma ressignificação das práticas de cada professora-aluna.

\section{Abordagem Metodológica}

O curso foi desenvolvido segundo a metodologia interacionista-problematizadora que é representada, principalmente, pelas seguintes estratégias:

Estratégias de problematização e provocação: nesta estratégia a equipe docente questiona, convidando os alunos à reflexão aprofundada e crítica sobre os pressupostos e as práticas convencionais. Incentiva as "explorações" de ideias, de recursos tecnológicos e de ações práticas desenvolvidas, promovendo reflexões sobre essas ações e pensamentos. Solicita esclarecimentos e justificativas de maneira que o aluno desenvolva a argumentação.

Estratégias de apoio à reconstrução: esta estratégia complementa a de problematização e provocação, pois se o docente atua no sentido de desequilibrar as certezas, propiciando que o aluno pense em novas heurísticas, ele também apoia a aprendizagem, sugerindo textos, sites, enfim, materiais para o embasamento da atividade que está sendo proposta. Esse tipo de intervenção tem como objetivo colocar em circulação ideias teóricas que possam ampliar a discussão. Considerando que os docentes assumem uma postura não diretiva, essas ideias não são apresentadas como verdades, ficando explicitado que se trata de postura interpretativa do docente frente aos conceitos e ideias (NEVADO et al., 2006b).

\section{Equipes Docentes}

O trabalho pedagógico foi desenvolvido por Professores, Tutores de Sede (tutores a distância) e Tutores de Polo (tutores presenciais). Os tutores de sede atuavam 
diretamente nas interdisciplinas, enquanto os tutores presenciais trabalhavam no polo, vinculados à interdisciplina Seminário Integrador.

Equipe docente do polo: em cada polo era constituída uma equipe composta pelos docentes das diversas interdisciplinas, juntamente com os tutores de polo e coordenadas por um professor membro da equipe do Seminário Integrador no polo.

Equipe docente de interdisciplina: composta pelos docentes que atuavam em uma mesma interdisciplina (um docente em cada polo) e pelos tutores de sede, sendo esta equipe responsável pelo desenvolvimento da proposta de trabalho, de forma articulada como as demais equipes.

\section{Processo Avaliativo}

O processo avaliativo era realizado em dois níveis complementares: a trajetória de aprendizagem das professoras-alunas no desenvolvimento das interdisciplinas e a avaliação integrada. Essa forma de avaliação (integrada) contava com a participação de toda equipe docente, sob a coordenação do Seminário Integrador. O foco dessa avaliação era apoiar a reflexão das professoras-alunas em torno do desenvolvimento do semestre. $O$ ponto central de apoio era o desenvolvimento de um portfólio de aprendizagem, desenvolvido ao longo do semestre. Sobre este, o aluno era convidado a fazer reflexões integradoras a partir de uma proposta de trabalho da equipe docente do curso como um todo.

Ao final de cada semestre era realizado um seminário de avaliação no qual cada professora-aluna produzia um texto, que, após comentado pelos docentes e revisado pelas professoras-alunas ${ }^{1}$, era apresentado em sessões públicas.

\section{Comunicação e Interação a Distância}

O trabalho a distância foi realizado com a participação intensiva dos tutores e professores, buscando manter um diálogo continuado, complementados pelo oferecimento de sugestões e encaminhamentos necessários ao prosseguimento dos trabalhos e às reconstruções necessárias em cada caso. Para viabilizar esta contínua interlocução, foram utilizadas diversas ferramentas de apoio ao trabalho cooperativo, tais como o ambiente ROODA ${ }^{2}$, blogs, wikis, fóruns e e-mail. Uma forma de gerar maior aproximação e melhorar as interações foi obtida com ferramentas ágeis de comunicação interpessoal como, por exemplo, o sistema Mensseger (MSN) de troca de mensagens.

\section{O Trabalho de Tutoria}

O trabalho de tutoria foi organizado no PEAD em duas grandes vertentes: a Tutoria nos Polos e a Tutoria de Sede (tutoria a distância). Enquanto a Tutoria de Polo tinha como missão primordial facilitar a integração dos indivíduos, a Tutoria de Sede tinha como missão primordial o suporte pedagógico para o desenvolvimento das interdisciplinas. Na prática, os tutores realizaram um trabalho integrado de apoio, buscando proporcionar a cada professora-aluna as condições necessárias para o desenvolvimento de suas atividades no curso, em consonância com suas diretrizes, notadamente a metodologia interacionista-problematizadora.

\footnotetext{
${ }^{1}$ Optamos por utilizar a expressão professora-aluna, no feminino, visto que, no curso, dos 400 alunos, 390 são mulheres. Assim, com essa expressiva maioria não nos sentimos ferindo a convenção da língua.

${ }^{2}$ Acessível em (www.ead.ufrgs.br/rooda) 


\section{Perfil dos tutores}

O grupo constituiu-se por 60 tutores, sendo 54 do sexo feminino e seis do sexo masculino. A média de idade dos tutores, situava-se em torno de 34 anos, sendo a idade mínima 24 anos e a máxima 65 anos. Dos 60 tutores que atuaram no PEAD, 47\% eram especialistas, $13 \%$ mestrandos, $27 \%$ mestres e $13 \%$ estavam cursando o doutorado.

\section{Tutoria de Sede}

O tutor de sede tem formação em pedagogia (ou, em casos específicos, outra licenciatura), ou formação em Educação em nível de mestrado e/ou doutorado, estando, portanto, apto a acompanhar as interdisciplinas do curso. Assim, salvo algumas exceções, os tutores trabalharam durante todo o curso e, na medida do possível, em um mesmo polo, o que lhes permitiu conhecer e acompanhar as professoras-alunas, desde os primeiros passos até o desenvolvimento do Estágio Docente e do Trabalho de Conclusão.

Assim, tinha-se para cada polo uma equipe de Tutores de Sede. Em cada semestre cada tutor de sede mantinha um vínculo específico com a equipe docente de uma determinada interdisciplina, dando suporte ao desenvolvimento de sua proposta pedagógica.

A sua atuação pedagógica pode ser sintetizada da seguinte forma:

Trabalhar a partir da pedagogia da pergunta, propondo questionamentos que apoiem os alunos na identificação de possíveis contradições ou inconsistências em suas produções vinculadas às atividades de uma interdisciplina (NEVADO et al., 2006b. p 27).

Este trabalho subtende que não basta ao tutor verificar se uma atividade foi cumprida ou não. É necessário que ela seja revisada e que um feedback seja apresentado através de "pareceres" que apoiem o aprendizado, propondo sempre questões que:

- Apoiem o aluno na identificação de inconsistências, quando for o caso, ou;

- Ajudem o aluno a perceber outras situações relevantes no contexto da atividade em desenvolvimento;

- Ofereçam suporte ao prosseguimento da atividade do aluno, seja através de reconstruções seja através de novas explorações.

As intervenções no desenvolvimento das atividades seguiam uma concepção que era planejada pelas equipes docentes, onde cabia aos docentes e aos tutores diferentes níveis de intervenção. Os tutores eram orientados pelos professores quanto às formas de feedback adequadas às diferentes atividades, e, em situações imprevistas, eles entravam em contato imediato com os professores para encontrar uma forma adequada para a intervenção, buscando com isso um melhor suporte às professoras-alunas.

A articulação entre tutores das diversas interdisciplinas foi fundamental para outra atividade, a de apoio à articulação entre os alunos, buscando identificar possíveis recomendações de parcerias, percebendo e indicando as possíveis aproximações na formação de grupos, consideradas as características das professoras-alunas e a natureza de suas classes de atuação docente. 
Assim, o trabalho de tutoria era feito de forma continuada, dando respostas a cada vez que uma professora-aluna dava andamento em suas produções. Para tanto se fazia necessário um trabalho diário do tutor, que, além de apresentar pareceres nas produções, realizar comentários, mantinha um contato direto de esclarecimento e apoio, utilizando principalmente ferramentas de comunicação síncrona, atendendo em um horário específico planejado para esta finalidade.

O incentivo, os lembretes quanto ao calendário e o convite ao prosseguimento das atividades acadêmicas faziam também parte da atividade da tutoria. Para materializar estas ações usavam-se todos os recursos disponíveis, desde a colocação de recados no portfólio, e-mail, chamadas no sistema de mensagem instantânea e, quando necessário, o telefone. Em um curso de formação em serviço para pessoas com idade média de 36 anos (ao iniciar o curso) e que trabalhavam em média 35 horas por semana, e que, pela primeira vez, estavam usando as TICs para mediação de curso completo de nove semestres, esta atividade era fundamental. O contato individualizado, o vínculo, a cumplicidade eram uma função imprescindível para lembrar a todos das conquistas já obtidas e da importância de ir em frente.

Para que isso pudesse acontecer, fazia-se necessário o suporte de um mapa de acompanhamento (um documento de edição cooperativa na web), que era construído pelo coletivo de tutores, com a coordenação da equipe do Seminário Integrador. E servia para dar visibilidade do andamento das atividades (cumprimento do calendário, necessidade de revisão etc.) tanto às próprias professoras-alunas quanto aos tutores e professores.

A tutoria do Seminário Integrador, além do apoio ao desenvolvimento específico da interdisciplina, realizava outra função importante, o suporte à avaliação integrada do eixo. Esta função consistia no acompanhamento do portfólio individual de aprendizagens ao longo do semestre e que se consolidava na construção do documento avaliativo individual.

A equipe de tutoria de cada polo participava do Workshop de Avaliação Integrada, formando banca de avaliação em parceria com um professor. Antecipando o Workshop, juntamente com o professor parceiro, participava da leitura do documento avaliativo individual e da construção das recomendações e do atendimento individualizado, apoiando os alunos em suas reconstruções, buscado com isso a qualificação da versão final do documento. Na sequência, a equipe oferecia suporte à organização da apresentação oral individual, e finalmente, participava da sessão de apresentação oral.

\section{Tutoria de Polo}

A Tutoria de Polo (tutoria presencial) era realizada em espaço físico oferecido pela prefeitura do município sede do polo, dotado de infraestrutura tecnológica computadores de ultima geração com acesso à Internet em banda larga, biblioteca, sala para encontros presencias coletivos e salas para atendimento individual. O trabalho era realizado diariamente, principalmente nos horário vespertino e noturno e tinha por finalidade principal servir de base de apoio à integração das professoras-alunas ao curso, principalmente nos semestres iniciais, quando não existia a familiaridade com a concepção do PEAD e com o uso intensivo das TICs.

No esforço inicial de integração, os tutores de polo desempenharam uma importante função na aproximação das professoras-alunas com os ambientes virtuais propostos pelo curso. Essa "alfabetização tecnológica" se constituiu em um grande desafio, superado com determinação pelas equipes de polo com o suporte a distância dos professores e 
tutores de sede. Nesta fase inicial, a ambiência no polo e a interação com o tutor presencial configuravam-se como um necessário apoio concreto para a criação de uma identificação com o curso.

Por ser um curso de formação em serviço, era fundamental que este contato fosse realizado por pessoas com formação adequada, conhecimento do funcionamento das redes públicas de ensino e das especificidades da docência nestas redes.

Este perfil mostrou-se fundamental para esclarecer as professoras-alunas nas questões relacionadas com a interação entre curso e trabalho, já que a proposta pedagógica do PEAD pressupunha essa estreita ligação, manifesta no seu princípio de articulação do fazer (nível da prática pedagógica) e do compreender (nível da teoria). Sendo também professor da rede pública, residente no município, o tutor de polo tinha amplo conhecimento dos detalhes necessários para facilitar a integração do aluno com o curso e deste com o seu trabalho, intercedendo, quando necessário, junto às equipes gestoras das escolas.

Superados os desafios iniciais, os tutores de polos puderam se dedicar mais ao acompanhamento individual das professoras-alunas. Um instrumento imprescindível para esta função foi a construção e acompanhamento das atividades de organização do tempo. Essa atividade levou muitas professoras-alunas a reprogramarem suas vidas, uma vez que o tempo disponível, muitas vezes, não se mantinha compatível com os requisitos do curso. Esse trabalho, em parceria com o Seminário Integrador, teve continuidade durante todo o curso e foi por certo um elemento importante na garantia da qualidade das aprendizagens e da prevenção da evasão.

A aproximação das professoras-alunas com as propostas pedagógicas das interdisciplinas também se constituiu em uma função importante. Para realizá-la o tutor de polo mantinha estreito vínculo com os tutores de sede, buscando estratégias para favorecer a aprendizagem das professoras-alunas. Embora houvesse uma interação sistemática com o tutor de sede e com os professores, via ambientes digitais, a proximidade física do tutor de polo e o conhecimento da realidade do aluno mostraramse indispensáveis.

$\mathrm{O}$ acolhimento das inseguranças, o incentivo ao prosseguimento do curso, o oferecimento de ajuda, a busca de cada professora-aluna que ameaçava fraquejar, seguido do apoio às retomadas, por certo contribuíram para o aumento da autoestima, da confiança e do estabelecimento da rede de aprendizagem, vitais para que as professorasalunas conseguissem chegar ao final do curso.

Com o desenrolar do curso, muitas das dificuldades das professoras-alunas foram atenuadas, e os tutores de polo puderam juntar esforços com os tutores de sede, auxiliando na revisão das produções das professoras-alunas.

\section{Formação dos Tutores}

Para a realização das funções de tutoria descritas acima, fez-se necessário oferecer formação aos tutores, tendo como eixo central o apoio à construção individual da concepção de tutoria proposta no projeto pedagógico do PEAD.

Antecipando o início do curso, foi realizada a primeira formação com carga horária de 160 horas, privilegiando as dimensões teórico-metodológicas e tecnológicas da tutoria. Com o início do curso, estas formações passaram a ser semanais ou quinzenais e, a partir do terceiro semestre, foi iniciado o Curso de Especialização em Tutoria (ESPEAD). 
O ESPEAD foi pensado como um espaço de formação continuada dos tutores. Essa formação foi desenvolvida a partir da formação de redes de interação, privilegiando uma formação fundamentada na forte interação entre teoria e prática a partir das ações de tutoria.

O currículo do ESPEAD foi planejado, considerando-se as flexibilizações necessárias às mudanças esperadas no contexto de um curso que se fundamenta numa construção coletiva. Ou seja, se reconstrói coletivamente a partir do seu projeto pedagógico, das experiências e das demandas que surgiam no percurso do PEAD. Esse espaço foi fundamental para as trocas, para reuniões, para os estudos teóricos e para a construção de um espaço de tutoria que seguiu a mesma arquitetura do PEAD. Essa formação se desdobrou em três eixos, como se descreve a seguir.

Oficinas tecnológicas - Essas oficinas privilegiavam a apropriação tecnológica, porém sem que houvesse uma dissociação entre a aprendizagem tecnológica e a aprendizagem teórico-metodológica. Para operacionalizar essa articulação, as oficinas ocorriam como apoio às atividades previstas. Na primeira formação, os participantes realizaram atividades presenciais e a distância, nas quais se apropriaram de ambientes e ferramentas que seriam usadas no decorrer do curso. Essas oficinas continuaram a acontecer na medida em que novas tecnologias precisavam ser introduzidas no curso.

Formação específica nas interdisciplinas - No início de cada eixo temático, ocorria uma formação específica em cada uma das interdisciplinas. Essas formações tinham a função de agrupar professores e tutores. Mesmo os tutores que não atuariam diretamente na tutoria de determinada interdisciplina participavam da formação. Nela, os professores apresentavam os materiais que seriam propostos às professoras-alunas, sendo, então, experimentados e avaliados pelos tutores, que registravam no pbworks suas considerações e discutiam com os professores sobre as atividades. A partir dessas discussões, alguns dos materiais eram repensados pelos professores, visando à sua adequação. É imprescindível que o tutor participe dessas discussões sobre os materiais e tenha acesso a eles antes do início do trabalho, pois ele só vai poder questionar e interagir com as professoras-alunas, se conhecer as atividades que estão sendo solicitadas. Muito mais do que realizar leituras ou participar dos encontros de formação, trata-se de um constante repensar e refazer a atividade de tutoria.

Seminários teórico-metodológicos - Esses seminários contemplavam estudos e debates interdisciplinares que visavam à discussão das arquiteturas pedagógicas utilizadas no curso, bem como à apropriação de metodologias de interação que permitissem ao tutor uma ação reflexiva.

Uma das atividades desenvolvida nesse seminário que trazemos para ilustrar foi a discussão em grupo das principais características que um tutor deveria apresentar. Após as trocas de atribuições, cada grupo apresentou aos colegas, e compilamos as características que eram comuns. As principais características elencadas para a função do tutor foram: i) colaborar para a construção de uma comunidade de aprendizagem; ii) dispor de tempo para atender às professoras-alunas; iii) valorizar as práticas das professoras-alunas; iv) promover o desequilíbrio das certezas; v) instigar a busca de informações sem dar respostas prontas; vi) conhecer os conteúdos trabalhados; vii) adequar a linguagem na mediação docente/tutor e tutor/professora-aluna; viii) ter atitude de cooperação e colaboração com os colegas tutores e professores; ix) ter habilidade tecnológica para usar as ferramentas e os AVAS utilizados no curso; $\mathrm{x}$ ) ter comportamento ético. 
Essas características foram amplamente discutidas no grupo - uma prática muito presente nas formações, em que todos têm espaço para expor suas ideias. Se alguma estratégia não está funcionando, discute-se para procurar soluções.

\section{Metodologia de Trabalho}

As formações foram desenvolvidas a partir de redes de interação e comunidades de aprendizagem com base na interdisciplinaridade e na construção cooperativa do conhecimento, privilegiando uma formação fundamentada na forte interação entre teoria e prática a partir das ações de tutoria.

Conforme referem Charczuk e Marques (2009b), o fato dos tutores exercerem a tutoria ao longo dos nove semestres, acompanhando interdisciplinas que poderiam trazer conteúdos diversos de sua área de formação inicial, reafirma a importância da formação dos tutores. Além disso, o fato de acompanharem as atividades destas interdisciplinas implica uma aproximação com a idéia de interdisciplinaridade. Nesse estudo, as autoras concluíram que os tutores fazem uma ligação entre essa ideia e o conteúdo curricular proposto no curso e também com o trabalho em equipe, sendo debatida por eles a necessidade de formação de equipes para possibilitar a efetivação do trabalho interdisciplinar.

No tocante ao uso da tecnologia, esteve sempre aliado à teoria e aos conteúdos que estavam sendo estudados. Esta é uma abordagem presente nas formações e nas atividades desenvolvidas com as professoras-alunas, sempre se vinculando a tecnologia ao contexto. É mais relevante compreender o funcionamento das ferramentas que treinar para o uso.

De acordo com o estudo proposto por Charczuk e Marques (2009a), os tutores apontam como aprendizagens desenvolvidas ao longo do curso um maior conhecimento sobre os conteúdos das diversas interdisciplinas, uma compreensão mais ampla sobre o desenvolvimento e aprendizagem das professoras-alunas, e da própria função de tutor. Como desafios e/ou dificuldades, os tutores referem a apropriação da função de tutor e a integração com a equipe, sendo que para superá-los engajam-se no estabelecimento de diálogo com professores e colegas.

Nos estudos sobre a construção da função dos tutores do PEAD (ZIEDE, 2008) o conceito de "tomada de consciência" (PIAGET, 1977) perpassa um conjunto de análises. Adquirindo grande importância, pois oferece os meios para se compreender a maneira como os tutores envolvidos no estudo conseguem evoluir na construção de outras perspectivas de formação de professores e na maneira de entender a metodologia do curso. A tomada de consciência auxilia o re-pensar das ações pedagógicas da função do tutor nas interações com as professoras-alunas do PEAD. Nestes estudos a autora constatou modificações importantes nas formas de feedback realizadas pelos tutores durante os quatro primeiros semestres do curso. A maior parte dos tutores realizou sistematicamente intervenções que desafiaram os alunos na direção da autoanálise e teorização das suas práticas, bem como apresentou maior facilidade no apoio ao processo de reconstrução.

\section{Avaliação da Atividade de Tutoria}

A avaliação do trabalho era realizada em três diferentes perspectivas, pelos próprios tutores, no contexto do curso de especialização, pelos professores parceiros ao final da cada semestre e pelas professoras-alunas em alguns semestres específicos. 
A avaliação no contexto do PEAD buscava fortalecer a formação e dar suporte à apropriação continuada da função de tutoria. Era realizada por três atores: pelo indivíduo, pelos pares e pelo professor orientador. Essa avaliação tomava por base um quadro de categorias e indicadores construído de forma cooperativa. As categorias identificadas foram: a) prática das concepções e metodologias do PEAD; b) atendimento aos alunos; c) interações com professores e tutores; d) fluência na telemática; e e) atitude profissional.

A avaliação dos professores parceiros (interdisciplinas) era realizada junto à coordenação através de um formulário com questões referentes a tópicos como: a) frequência de acesso para dar feedback às professoras-alunas; b) qualidade do feedback; c) acompanhamento da realização de atividades pelos alunos; d) disponibilidade e participação nas reuniões de equipe; e) atitude de cooperação e de colaboração; f) iniciativa para ajudar os estudantes nas suas dificuldades; g) interesse e atitude na autocapacitação e participação em atividades de formação; h) integração com a equipe de tutores; i) integração com os professores; $j$ ) atendimento adequado e em tempo das solicitações dos docentes; 1) fluência tecnológica adequada para dar apoio aos estudantes no uso dos ambientes e artefatos requeridos por sua interdisciplina; $m$ ) e por fim, uma indicação do interesse em uma parceria em novas oportunidades.

Foram ainda realizadas avaliações, buscando conhecer o grau de satisfação das professoras-alunas com respeito às equipes de tutoria (polo e sede). Nestas, levantou-se aspectos tais como, a formação pedagógica, a fluência tecnológica, o grau de disponibilidade, a presteza do atendimento e o grau de "urbanidade".

\section{Considerações Finais}

Os estudos sobre a tutoria no PEAD possibilitaram um olhar sobre esta função ainda em construção. Ao acompanhar as interações dos tutores desde o início do curso, percebemos o quanto eles foram modificando suas concepções e seus modos de interação no processo de interlocução para a elaboração-execução das atividades com as professoras-alunas. A percepção dessas transformações se deu a partir do acompanhamento das interações, dos retornos das professoras-alunas e da participação na formação continuada.

Para que ocorra um trabalho em equipe, os tutores necessitam ter um bom relacionamento tutor/professor/aluno. As reuniões com os professores, tutores $\mathrm{e}$ coordenadores foram fundamentais para "afinar" esse trabalho. O vínculo afetivo que os tutores estabeleciam com as professoras-alunas foi essencial para este trabalho, pois os professores das interdisciplinas atuavam em semestres específicos, enquanto os tutores seguiam no acompanhamento, sendo este parceiro, com o qual as professoras-alunas compartilhavam experiências, suas dificuldades, seus potenciais e suas angustias.

O trabalho do tutor, consoante com sua natureza docente, requer muito mais que o conhecimento sobre um campo de estudo. Para encontrar o momento mais adequado para uma intervenção, é preciso estar ciente da situação e conhecer o perfil e a história de vida de cada professora-aluna. Este trabalho demanda organização de tempo, conhecimento pedagógico, tecnológico e capacidade para planejar estratégias de intervenção. Para realização de intervenções, tanto online como presencial, é necessário muita habilidade, pois problematizar, esclarecer dúvidas, auxiliar as construções e acompanhar postagens são atividades desempenhadas diariamente.

A estratégia adotada no projeto mostrou-se adequada, na medida em que para os tutores ocorria também uma formação em serviço e, desta forma, podiam perceber com maior 
sensibilidade as dificuldades das professoras-alunas. $O$ fato de suas interações serem supervisionadas dava-lhes mais segurança, ao mesmo tempo em que possibilitava um contínuo processo de reflexão.

No decorrer do trabalho, os tutores tomaram consciência das características do Curso baseado na proposta interativa e construtivista, pouco adotada na maioria das instituições. Também perceberam a importância do vínculo e da troca com seus colegas e com os professores. Os tutores caminharam na direção do fortalecimento da comunidade de aprendizagem no curso e fora dele, pois muitos trabalhavam em escolas e universidades, levando, desta maneira, o trabalho inovador do PEAD para seus alunos.

\section{Referências}

CHARCZUK, S. B.; MARQUES, T. B. I. Concepções e práticas interdisciplinares no trabalho dos tutores de sede do Curso de Pedagogia a Distância. Trabalho de Conclusão do Curso de Especialização em Tutoria em Educação a Distância - ESPEAD Porto Alegre: UFRGS, 2009a.

CHARCZUK, S. B.; MARQUES, T. B. I. Concepções de tutores de sede de um curso de pedagogia na modalidade a distância acerca do conceito de interdisciplinaridade. Schème - Revista Eletrônica de Psicologia e Epistemologia Genéticas. Volume 2, Número 4, Ago-dez 2009b.

Commonwealth of Learning, Tutoring in Open and Distance Learning: A Handbook for Tutors, Canadá, 2003.

NEVADO, R. A.; CARVALHO, M. S.; BORDAS, M. C. Licenciatura em Pedagogia a Distância: anos iniciais do ensino fundamental. Guia do tutor. PEAD/UFRGS: Gráfica da UFRGS, 2006a.

NEVADO, R. A.; CARVALHO, M. J. S; MENEZES, C. S. Licenciatura em pedagogia a distância: guia do professor. Porto Alegre: Gráfica da UFRGS, 2006b.

NEVADO, R. A. de N.; CARVAlHO, M. J. S. de; MENEZES, C. da S. de (org.). Aprendizagem em rede na educação a distância: estudos e recursos para a formação de professores. Porto Alegre: Ricardo Lenz Editor, 2007, v., p. 121-136.

PIAGET, J. A Tomada de consciência. São Paulo: Melhoramentos, 1977.

PRETI, Oreste. O estado da arte sobre tutoria: modelos e teorias em construção, 2003,

Disponível em: <http://www.uab.ufmt.br/uab/images/artigos_site_uab/tutoria_estado_arte.pdf>. Acesso em: ago. 2010.

SANTOS, VANICE; ZIEDE, M.L.; CHARCZUK, .S. B.; NEVADO, R. A. Tutoria Em Educação a Distância: Experiências, Aprendizagens e Práticas no Ensino Superior. Anais, in: XV ENDIPE Encontro Nacional de Didática e Prática de Ensino, 2010. Belo Horizonte, 2010 p. 1-24.

ZIEDE, M. L.; CHARCZUK, S. B.; NEVADO, R. A. The use virtual cooperative environments in training of tutors for distance education. In: GONÇALVES, S. (org.). Creativity and Innovation. Coimbra: ESEC, 2009, v. 1, p. 63-73.

ZIEDE, M. K. L A Construção da Função dos Tutores no Âmbito do Curso de Graduação em Pedagogia na modalidade a Distância da Faculdade de Educação da Universidade Federal do Rio Grande do Sul, 2008. Dissertação de Mestrado FACED/UFRGS. 